\title{
Developing reflection on competence-based learning: the Russian experience with the Tuning approach
}

\author{
Anna Serbati and Alessio Surian
}

\begin{abstract}
The paper focuses on the Tuning Russia project. It aims at providing an overview of the impact of the Tuning methodology and outcomes concerning University teaching, learning, and assessment activities. It identifies: the most relevant results and "lesson learnt" during the project; tools/concepts/experiences that involved teachers found most interesting; strengths and weaknesses; the usefulness of working with colleagues from different Russian universities; and the level of sharing of the Tuning methodology with other colleagues within participating Universities. The empirical data for the study were drawn from a qualitative questionnaire with open questions filled-in by the members of the subject area group "Social Work" involved in the Tuning Russia project. The respondents were six academic teachers from different Russian universities and two European Tuning experts. This reflection by academic teachers upon the initial implementation of the Tuning approach in Russia highlights the opportunities to explore methods of establishing and improving communities of practice in the field of competence-based higher education curriculum development. Results highlight the need to develop further work concerning both summative and formative evaluation in relation to competence-based curricula review in higher education.
\end{abstract}

Keywords: Competence-based learning; student-centred approach; reflection; learning and teaching; community of practice; feedback.

\section{Theoretical framework: competence-based learning and new conceptions of teaching}

Nowadays universities are faced with the challenge of implementing continuous change and improvement to courses and with the development of a better educational offer for young people. The Bologna process represents for European countries a cultural revolution in the field of higher education requiring changes in the structure, the approach, the responsibilities and the contents of academic courses. A core issue concerns the role of learner, i.e. the learner having a central position within the learning process. Expected learning outcomes concern knowledge as well as skills and competences, both subject specific and generic. The focus on the competences that the students must have achieved by the end of their learning process was 
confirmed and spelled out through the adoption of the Framework for the Qualification of the European Higher Education Area (EHEA) in 2005.

This paper focuses on the Tuning Russia project, a component of the Tuning Academy's programme to facilitate the Bologna Process in Europe and to promote a student-centred approach in higher education institutions worldwide. It aims at providing an overview of the Tuning methodology impact and outcomes concerning teachers, courses, universities, and the Russian universities network. ${ }^{1}$

Literature on teaching in higher education has developed specific research fields concerning teacher conceptions of teaching ${ }^{2}$ and competence-based learning. ${ }^{3}$ The concept of "competence" refers to a quality, ability, capacity or skill that is developed by and belongs to the student. Competences are developed in all course units and assessed at different stages of a programme. Some competences are subject-area related (specific to a field of studies), while others are generic, ${ }^{4}$ since students develop in their careers an integrated body of knowledge and skills from many different disciplines as well as transferable skills such as problemsolving, critical and creative thinking, communication and leadership skills.

In this context, the Tuning methodology offers concepts and operational tools to align Higher Education programmes with agreed learning outcomes and competences and qualification levels, answering to the need of labour market as well as the need of young people. To design courses based on intended learning outcomes (ILO) that are consistent and aligned with related teaching, learning and assessment techniques, it is crucial to apply a

1 Yevgeniya V. Karavayeva and Yelena N. Kovtun, "Adapting the Tuning Programme Profiles to the Needs of Russian Higher Education," Tuning Journal for Higher Education 1(2013): 187-202.

${ }^{2}$ Lyn Gow and David Kember, "Conceptions of teaching and their relationship to student learning," British Journal of Educational Psychology 63(1993): 20-33; David Kember, "Teaching beliefs and their impact on students' approach to learning," in Teaching and Learning in Higher Education, ed. Barry Dart and Gillian Boulton-Lewis, 1-25 (Camberwell, Australia: Australian Council for Educational Research, 1998); Keith Trigwell, Michael Prosser, and Philip Taylor, "Qualitative differences in approaches to teaching first year university science," Higher Education 27 (1994): 75-84; Katherine Samuelowicz and John D. Bain, "Revisiting academics beliefs about teaching and learning," Higher Education 41(2001): 299-325.

3 Aurelio Villa Sánchez and Manuel Poblete Ruiz, eds., Competence-based learning (Tuning Project, Bilbao: University of Deusto, 2008); Richard A. Voorhees, "CompetencyBased Learning Models: A Necessary Future," New directions for institutional research 110 (2001):5-13.

4 Jenneke Lokhoff et al., A Guide to Formulating Degree Programme Profiles (Bilbao, Groningen, and The Hague: Universidad de Deusto, 2010). 
programme designing approach which optimises the conditions for the quality of learning. ${ }^{5}$ This approach requires a personal commitment by the teacher who focuses on the students' learning outcomes and considers these the main goal of the learning and teaching process.

The model presented by Biggs is called "constructive alignment". It is based on the constructivist perspective that highlights how learners use their own activity to construct their knowledge. Students build meanings by using relevant learning activities and, knowing which and at what level educational courses should pitch the expected learning outcomes, find it is easier for them to feel motivated and interested in the contents and in the activities designed by the teacher in order to facilitate their learning process. In this learner-centred model students "will be able to study by themselves, learning what is essential more effectively, and knowing how to use and present what they learn" ${ }^{6}$ The teacher's role is to describe in detail the learning activity and to specify the context and the standard the students should attain. The "alignment" means that the learning activity, which is functional to the expected outcomes, needs to be fostered by teachers creating a learning environment that allows students to undertake those learning activities and then to verify with appropriate assessment tools whether the outcomes have been achieved.

This implies using active teaching methods such as problem-based learning, which is significantly more effective than traditional instruction to train competent and skilled practitioners and to promote long-term retention of knowledge and skills acquired during the learning experience.?

Therefore, changes are needed in the way teachers usually think about teaching: while lectures and tutorials are the default teaching methods, a shift towards a student-centred approach requires teachers to review and to identify the types of situations in which different teaching/learning activities can be organised, depending on the learning outcomes that are intended. The term 'lecture' focuses on what teachers should do, but it is more important to focus on what the students are doing; in that sense, the teacher becomes a learning facilitator, somebody who leads self-directed learning processes through interactive session and who triggers critical reflection and thinking. This is reflected in the following statement: "The Tuning community should

\footnotetext{
5 John Biggs, Teaching for Quality Learning at University (Buckingham: Open University Press, 2003).

${ }^{6}$ Javier Burón Orejas, Enseñar a aprender. Introducción a la metacognitión. (Bilbao: Mensajero, 1993).

7 Johannes Strobel and Angela van Barneveld, "When is PBL more effective? A metasynthesis of meta analyses comparing PBL to conventional classrooms," The Interdisciplinary Journal of Problem based Learning 3, 1(2009): 44-58.
} 
build skills for innovation as an integral part of its agenda on competencebased approaches to curriculum".

Since Tuning ${ }^{9}$ is a bottom-up approach, this study focuses on the development of individual and collaborative reflection as key vehicle for the construction of teacher knowledge and effective and meaningful teaching practices oriented to enhancing students' competences for their personal and professional lives. It also explores ways to relate such a bottom-up approach to opportunities offered by "communities of practice" approach, ${ }^{10}$ especially when framed from the Engeström ${ }^{11}$ collective activity and learning perspective.

\section{Follow-up analysis of Tuning Russia impact and outcomes}

This paper presents a reflection on the Tuning core principles and concepts developed by a group of Russian academic teachers and European colleagues during the Tuning Russia project (2010-2013). The main goal of this study is to understand the impact of the Tuning approach on the development of new courses as well as improvement of the existing ones by using a competence-based approach.

The empirical data for this study was drawn from a qualitative questionnaire with open questions filled by the members of the subject area group "Social work" involved in the Tuning Russia project. The respondents were six academic teachers from different Russian universities and two European Tuning experts. The main issues investigated are the following: the present and future impact of the Tuning methodology upon University teaching, learning and assessment activities; the most relevant results and "lessons learnt" during Tuning Russia; tools/concepts/experiences that the involved teachers found more interesting; strengths and weaknesses; the usefulness of working with colleagues from different Russian universities; the level of sharing of the Tuning methodology with other colleagues within participating Universities.

${ }^{8}$ Francesco Avvisati, Gwenaël Jacotin, and Stéphan Vincent-Lancrin, "Educating Higher Education Students for Innovative Economies: What International Data Tell Us," Tuning Journal for Higher Education 1(2013): 237.

9 Julia González and Robert Wagenaar, TUNING Educational Structures in Europe II. Universities' contribution to the Bologna Process. Final report Project Phase II (Universidad de Deusto / Universiteit Groningen: Deusto University Press, 2005).

${ }^{10}$ Etienne Wenger, Richard Arnold McDermott, and William Snyder, Cultivating communities of practice (Boston: Harvard Business School Press, 2002).

11 Yrjö Engeström, "Expansive learning at work: Toward an activity theoretical reconceptualization," Journal of Education and Work 14 (2001): 133-156. 
After several informal discussions and reflections on Tuning main concepts, formal comments on these were collected at the end of the project, to allow all involved staff to outline their understanding of the methodology, as well as their beliefs and their perceptions concerning the changes that occurred in their teaching practices. The follow up questionnaires (administered 4 months after the project final conference) aimed at collecting opinions by academics after a period of personal re-working of concepts and tools and collective sharing of them with colleagues in different institutions and different contexts.

Based on content analysis supported by the use of the Atlas.ti software, the results highlight several emerging dimensions. They have been grouped in categories, based on categories found in previous literature and on a mixed approach combining bottom-up data analysis and top-down inferences based on previous studies key topics. Instead of seeking to decide beforehand the role of competence-based learning in (re)designing curricula and teaching activities, the aim of the qualitative and data-driven analysis used was to create a dialogue between the data and the interpretations by the researchers. ${ }^{12}$

\section{Results and impacts on academic teachers' competences towards the development of a community of practice}

\section{Strengths and weaknesses of the project}

Since 2001, the 'Dublin Descriptors' have been adopted as cycle descriptors for the qualification framework of the European Higher Education Area. The introduction of the Dublin Descriptors ${ }^{13}$ has guided countries to provide courses according to a three-level structure - not only in terms of knowledge, but mainly in terms of skills and competences which guarantee more flexibility and customization within programmes. Thus, higher education's responsibility became not only to guarantee updated knowledge and subjects, but also to provide students with "learning behaviours" 14 such as problem solving, interaction and communication, critical reflection,

${ }^{12}$ David Silverman, Interpreting Qualitative Data. Methods for Analysing Talk, Text and Interaction (London: Sage, 2001).

13 These are generic statements about achievements and abilities that students should acquire at the conclusion of each programme: knowledge and understanding; applying knowledge and understanding; making judgements; communication skills; and learning skills.

${ }^{14}$ High Level Group on the Modernisation of Higher Education, "Report to the European Commission on Improving the quality of teaching and learning in Europe's higher education institutions," (Brussels: European Commission Brussels, 2013). 
meaning making, self-correction, and ability to learn continuously from formal, non-formal and informal contexts.

Participants identify as a major result of Tuning Russia "the revision of study programme on the basis of shared competences and learning outcomes", 15 in terms of measurable results of a learning experience which allows to ascertain to what extent a competence has been formed or enhanced. ${ }^{16}$ From the content analysis (extracts from the answers are reported in quotes) the key strengths identified by participants within the Tuning approach relate to the opportunity to "develop and select competences according to Tuning methodology" and "the competences passport, an instrument describing the methodology of defining competences based on the needs of different actors (employers, students, professors)". Some of the teachers feel that the work implemented so far provides the key elements to plan further work in several academic areas and to develop step by step a benchmarking approach.

The consultation process ${ }^{17}$ (Figure 1) shows an awareness of the need to improve the dialogue between universities and business dialogue, as recommended by the European Commission: "Knowledge transfer between universities and enterprises will work best where there is a general framework of cooperation and mutual understanding, involving partnerships, joint projects and the exchange of people".$^{18}$ According to one participant, "Russian higher education needs reforms including not only a multilevel system of education but the development of lifelong learning system. In this case Tuning would become a methodology which makes it possible to develop efficiently professional competences in accordance with the changing needs of the labour market."

Participants mention that the project has been an opportunity to share and to discuss "interesting theories" concerning Pedagogy and Social Work and to test such theories by putting them into practice. The project has also provided an opportunity to share ideas concerning Social Work, to develop a

${ }^{15}$ Please note that in this quotation as well as in the following ones, italics is used to cite the wording of questionnaires proposed at the end of Tuning Russia Project, translated from Russian into English; therefore the language may have been modified slightly for purposes of clarity.

${ }^{16}$ Jenneke Lokhoff et al., eds., A Guide to Formulating Degree Programme Profiles (Bilbao, Groningen, and The Hague: Universidad de Deusto, 2010).

17 Tuning organises a large-scale consultation among graduates, students, employers and academics to identify the most important generic competences for each of the academic fields involved.

${ }^{18}$ Commission of the European Communities, "A new partnership for the modernisation of universities: the EU Forum for University Business Dialogue" (COM(2009) 158 final, Brussels: European Commission), 5. 
thorough conceptual framework of the Social Work subject area, and to identify a set of key tools for developing a degree programme that takes into account the current European practice and debate.

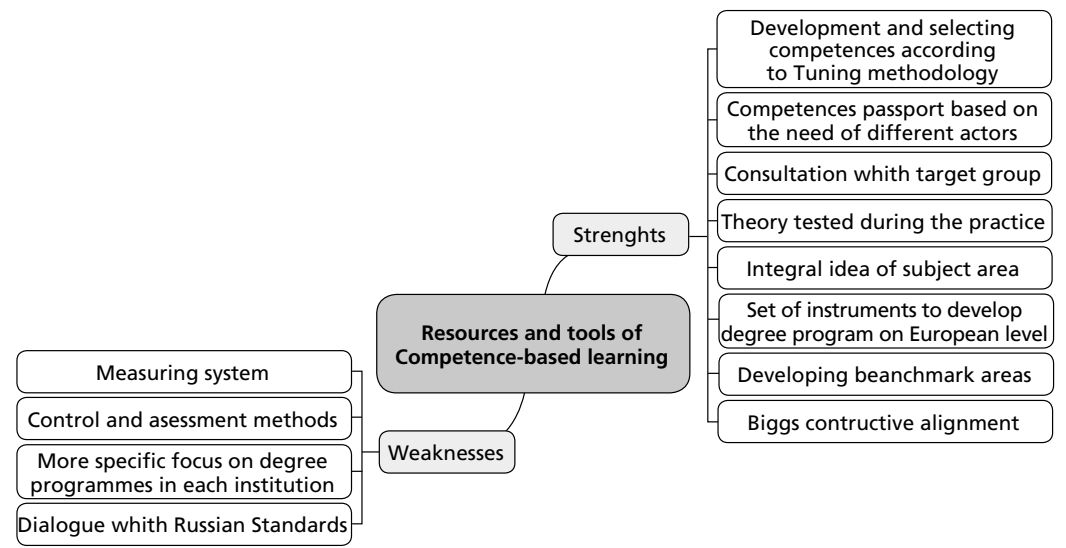

Figure 1

Strengths and weaknesses of the projects

Nonetheless, benchmarking and assessment are also mentioned among the critical issues and the actual weaknesses of the Tuning Russia project. A key weak point has been the timing of the implementation of the project in Russia while "at the same time new standards were adopted" 19 and such standards seem "incompatible with the Tuning methodology". In addition, the actual "implementation period of the project is not clear", while there are still open "questions" concerning the Social Work subject area.

The main concerns are that "assessment and assessment methods were not discussed enough" during the implementation of the project and that within the project "the system of assessment was represented rather fragmentarily". As a result, so far there is a perception that there is a lack of assessment tools, and an awareness that "the competence measuring system is not sufficiently developed".

${ }^{19}$ During the last 2-3 years, Russian higher education institutions (HEIs) have (re) designed and implemented educational programmes following Federal State Educational Standards (FSES) guidelines. Universities, academies and institutes in Russia follow these standards, which designate educational programs requirements for graduates and workload content. For more information see: Yevgeniya V. Karavayeva and Yelena N. Kovtun, "Adapting the Tuning Programme Profiles to the Needs of Russian Higher Education," Tuning Journal for Higher Education 1 (2013): 187-202. 
The remarks of the Tuning Russia academic staff provide evidence of a sensitivity of the need to develop further work concerning both summative and formative evaluation in higher education. The actual implementation of the Tuning Russia project provided limited space for discussing and finalising assessment tools. The focus was on curriculum development and the main contribution concerned the identification of key curriculum evaluation elements, especially with reference to the Tuning checklist for curriculum evaluation. This provides selected focal issues and questions concerning the educational process, the educational outcome, and the means and facilities required for programme delivery. The checklist is part of the Tuning Toolkit for the (re)design of ECTS-based degree programmes. ${ }^{20}$ Within this framework, "evaluation" is concerned with judgments focusing on courses and course delivery, and especially concerning the process of making of such judgments. Scriven ${ }^{21}$ helps to focus on the "assessment" dimension which is concerned with judging students' work according to specific, weighted set goals and based upon a preliminary justification of (a) the data-gathering instruments or criteria, (b) the weightings and (c) the selection of goals. Within this perspective, the Tuning approach can be instrumental in providing evidence on how to justify a judgment made against the stated goals and criteria. In the case of the Tuning Russia project, this would imply follow-up activities concerning both formative and summative assessment. ${ }^{22}$

In particular, the feed-back and self-regulation aspects enhanced by formative assessment would seem to relate well with improving the quality of monitoring activities concerning the implementation of competence based approaches to curriculum development and specifically of the Tuning approach. Literature review indicates that students who are effective at selfregulation produce better feedback and are more able to use the feedback they generate to achieve their desired goals. ${ }^{23}$ Therefore, specific focus on feedback and self-regulation would offer an opportunity for faculties to

20 Tuning Checklist for Curriculum Evaluation is included in the annex 2 of the publication: Julia Gonzalez and Robert Wagenaar, eds., Tuning Educational Structures in Europe. Universities' Contribution to the Bologna Process. An Introduction, $2^{\text {nd }}$, ed. (Bilbao and Groningen: University of Deusto, 2008), available at: http://www.unideusto.org/tuningeu/ images/stories/Publications/ENGLISH_BROCHURE_FOR_WEBSITE.pdf

${ }^{21}$ Michael Scriven, "The methodology of evaluation," in Perspectives on Curriculum Evaluation (AERA Monograph Series - Curriculum Evaluation), ed. Ralph W. Tyler, Robert M. Gagné, and Michael Scriven (Rand McNally and Co, 1967), 40.

Mantz Yorke, "Formative assessment in higher education: moves towards theory and the enhancement of pedagogic practice," Higher Education 45, 4 (2003): 477-501.

${ }^{23}$ Debora Butler and Philip Winne, "Feedback and self-regulated learning: a theoretical synthesis," Review of Educational Research 65, 3 (1995): 245-281. 
engage in dialogue and to gather significant monitoring data concerning progress towards Tuning goals.

From this perspective, it would be helpful to devote specific attention to the practice of obtaining effective feedback, and to take into account the results of research literature in this field for instance Nicol and MacfarlaneDick $^{24}$ who identify the following seven principles of good feedback practice:

1. Helps clarify what good performance is (goals, criteria, expected standards).

2. Facilitates the development of self-assessment (reflection) in learning.

3. Delivers high quality information to students about their learning.

4. Encourages teacher and peer dialogue around learning.

5. Encourages positive motivational beliefs and self-esteem.

6. Provides opportunities to close the gap between current and desired performance.

7. Provides information to teachers that can be used to help shape teaching.

Teachers who are able to facilitate such a feedback process should find themselves better able to discuss and understand assessment criteria with peers and students, and to provide targeted feedback to learners which would encourage reflection and critical thinking.

In turn, these dimensions of formative assessment would link well with the use of the rubric, articulating the expectations for an assignment by listing the criteria (i.e. what counts), and describing the levels of quality. ${ }^{25}$ Rubric use is associated with improved academic performance and the potential of rubrics to identify the need for improvements in courses and programmes has been demonstrated. According to a literature review by Reddy and Andrade, ${ }^{26}$ "studies of the validity of rubrics have shown that clarity and appropriateness of language is a central concern" and "can lead to a relatively common interpretation of student performance", features that relate well to Tuning's core concerns. Two recommendations by Reddy and Andrade $^{27}$ seem particularly relevant in assessing the use of rubrics in implementing and monitoring a Tuning project.

${ }^{24}$ David J. Nicol and Debra Macfarlane-Dick, "Formative assessment and self-regulated learning: a model and seven principles of good feedback practice," Studies in Higher Education 31, 2 (2006), 205.

${ }^{25}$ Judith Arter and Jan Chappuis, Creating and recognizing quality rubrics (Upper Saddle River, NJ: Pearson/Merrill Prentice Hall, 2007).

${ }^{26}$ Y. Malini Reddy and Heidi Andrade, "A review of rubric use in higher education", Assessment \& Evaluation in Higher Education 35, 4 (2010): 435-448.

${ }^{27}$ Ibid., 446. 
These authors indicate that there is a need for more research on the validity and reliability of the rubrics. Tuning projects could be instrumental in conducting pilot and reliability tests prior to the implementation of rubrics, and in providing information about the procedures, analyses and results. In addition, Reddy and Andrade claim that higher education institutions should have a closer focus on learning, to avoid using rubrics only for evaluation purposes: "The ways in which they can be used to teach has not been sufficiently addressed. Studies are needed that look beyond scores for an assignment by examining, for example, the development of positive attitudes towards and perceptions about learning, the acquisition and integration of new knowledge, extending and refining knowledge, using knowledge to perform meaningful tasks, and developing powerful habits of mind that enable students to regulate their behavior and think critically and creatively."

\section{Lessons learnt and relevant impacts}

Participants' answers concerning the most relevant impact of and the lessons learnt from the Tuning project, show a willingness to move "from subject-centred education to competence based learning and student-centred one", and to promote "the development of competences and their correlation with the modular structure of the degree program for teaching Social Workers". For some teachers, "all the aspects of the Tuning programme are important but the most interesting is the notion of competences and the difference between the concept of "competences" and the concept of "result". I saw interconnections of all the parts of (the) main educational programme"; moreover, "the lesson on the levels of the mastery of competences, which gives an idea of how and what is to be evaluated" and the "system of interdependence of competences and learning outcomes." are considered as relevant outcomes of the whole project. The Commission of the European Communities ${ }^{28}$ notes that countries in Europe and outside of Europe are increasingly focusing on: a comprehensive change to curricula and learning methods towards the inclusion of transversal and transferable skills; better examination methods, more geared towards the assessment of learning and competences; greater diversification of admission profiles and approaches to learning in order to tap talent from non-traditional backgrounds, including adults returning to study; greater interdisciplinarity and transdisciplinarity of education and research agendas.

${ }^{28}$ Commission of the European Communities, "A new partnership for the modernisation of universities: the EU Forum for University Business Dialogue,” 4. 
Tuning represents an answer to the above mentioned activities through the development of a competence-based approach and through the sharing of common instruments for translating into practice the use of competences and learning outcomes. The dimensions including the concepts, tools, applied elements, reflections on issues discussed and their implementation, on curricula design and implementation may be interpreted as pedagogical competences gained and, or developed by teachers during the project (Figure 2.)

Since "all staff teaching in higher education institutions in 2020 should have received certified pedagogical training and continuous professional education as teachers should become a requirement for teachers in the higher education sector", ${ }^{29}$ the Tuning methodology may contribute to this major goal; such a contribution could be related to the cross-fertilization through the building of Tuning Centres in Russia and other training activities.

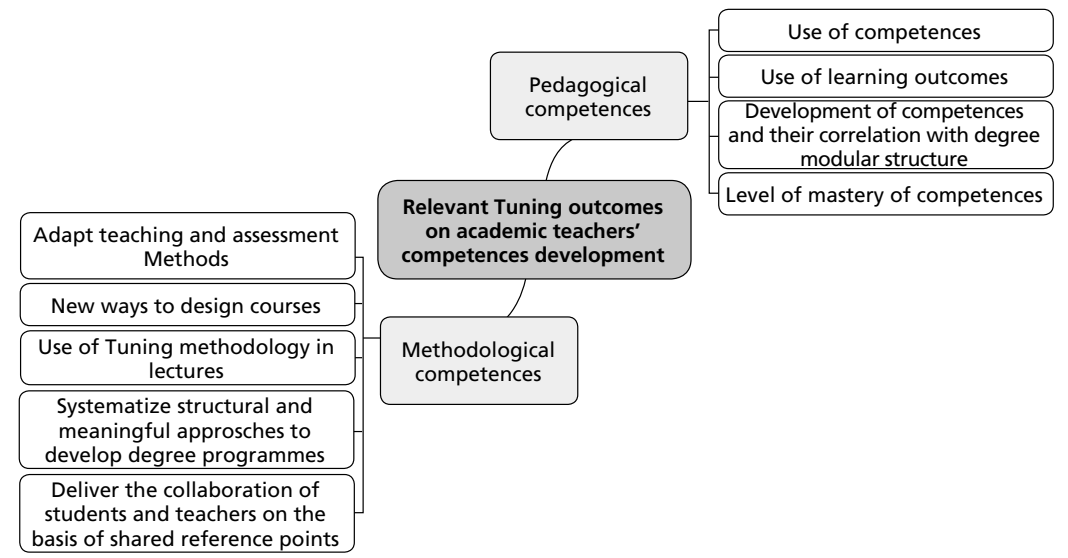

Figure 2

Relevant Tuning outcomes on academic teachers' competences development

The teaching staff involved in the Social Work group of Tuning Russia project outline as well the possibility to "systematize structural and meaningful approaches to develop degree programmes" and to "deliver the collaboration of students and teachers on the basis of shared reference points." The "technology of creation of basic education programmes and work plans has been reconsidered" after comprehension and reflection during the project some of them "started to use the Tuning methodology in the lectures".

${ }^{29}$ High Level Group on the Modernisation of Higher Education, "Report to the European Commission on Improving the quality of teaching and learning in Europe's higher education institutions" (Brussels: European Commission, 2013), 32. 
While institutions have almost understood and implemented the practice of course description using a learning outcomes framework, the related and required changes in terms of teaching and assessment have not necessarily followed. Such changes in paradigm require a more complex role for academic teachers and the development of new competences to allow them to design and to deliver appropriate teaching and assessment activities. These comprise: the development of subject specific competences as well as pedagogical competences and interactive methods; reflection on teaching practices; managing and sharing leadership responsibilities; organizational and communicative issues; building community partnerships for learning and international networks; and participating in continuing professional development.

If one considers a teacher-centred and a student-centred approach as a continuum in terms of the teachers' approaches, one can identify different and dynamic teacher profiles, depending on the context, the subject, and the cultural conception of highereducation..$^{30}$ Teachers' answers to the questionnaire indicate an acknowledgement that Tuning approach aims at developing strategies to facilitate a "change in the attitude of teachers to develop work programs [...] as well as new teaching methods and control". The use of competences and expected outcomes in curriculum development should not turn into a bureaucratic change: it requires re-thinking of traditional academic positions in order to provide room for the development of students in selfdirected learning: "I think that the teaching methods for the social workers should be changed. The developing of the competences required new methods of teaching that we learnt during the project". The clear connection between learning and teaching methods emerges in the following sentence: "Social work bachelor and master degree educational programmes based on Tuning methodology have been developed including the design of competences and results, evaluation tools and methods of control; work plans for the academic disciplines are based on competence and the results; methodology correlates with the methods of teaching and methods of control." Different methods and learning environments may produce very different learning.

The teaching challenge is to teach in a way that encourages students to implement a deep approach to learning - involving higher cognitive level processes. ${ }^{31}$ According to Biggs, "learning activities that are at too low a level to achieve the intended learning outcomes are referred to as comprising

${ }^{30}$ Lin Norton et al., "Teachers' beliefs and intentions concerning teaching in higher education," Higher Education 50 (2005): 537-571.

${ }^{31}$ Sabine Hoidn and Kiira Kärkkäinen, "Promoting Skills for Innovation in Higher Education: A Literature Review on the Effectiveness of Problem-based Learning and of Teaching Behaviours" (OECD Education Working Papers Nº 100, OECD Publishing, 2014). 
a 'surface' approach to learning, for example memorising to give the impression of understanding. Activities that are appropriate to achieving the outcomes are referred to as a 'deep' approach." 32 The University should require students to progressively describe, comprehend, relate, argue, explain, analyse and solve problems close to and distant from the subject, relate to principle, hypothesise and reflect.

All the above-mentioned elements have been grouped into the academic methodological competences of teachers. One can observe that the pedagogical competences and the methodological competences are very related, since they concern theories, methods and tools to deliver good teaching and to improve teaching practices.

\section{Developing a new culture of sharing}

Furthermore, the project provided an opportunity to "study the experience of colleagues from Spain, Italy, Russia" and to "start to use the Tuning methodology in lectures". Tuning Russia created a space for shared exchanges involving teachers from different institutions, with the scope to construct a learning community for individual and collective spaces. Such spaces aim at developing reflection on teaching practices, towards the construction of meta-profiles, i.e., identifying referential elements that reflect upon and analyse possible diverse degree profiles, for designing and delivering degree programmes.

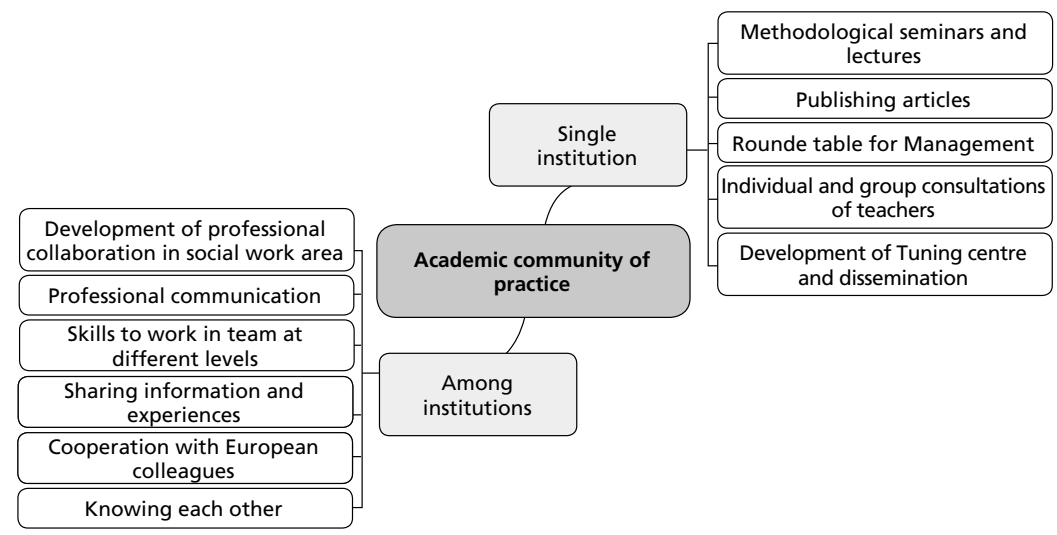

Figure 3

Academic community of practice

32 John Biggs, Teaching for Quality Learning at University (Buckingham: Open University Press, 2003), 29. 
Some teachers outlined as a positive effect the "development of professional collaboration in (the) social work subject area, conducting joint seminars, conferences" as well as that "cooperation among universities has been broader, (there) have been several conferences, we are writing articles, (and) cooperate with each other on a regular basis". Tuning Subject Area Groups comprise teachers from different universities, also cooperation among different Russian and European institutions constituted an important factor and an opportunity for the "exchange of experience, business connections, the experience of work in team of different universities from Russia and European Union".

The development of a sharing culture offered people a chance to "know each other; continue to cooperate; share information and experience" and learn from each other in relation to previous experience in curriculum planning and teaching. Moreover, some institutions created methodological seminars within their departments and organised lectures for advanced qualification courses at the University. These two types of activity proved to be a good way to disseminate the methodology and also to create a culture of reflection on the various Tuning concepts. In one case "Tuning methodology was introduced for teachers at advanced qualified courses and for postgraduate students at special seminars."

An interesting point was the creation of Tuning centres. They have been set up in order to go beyond the project implementation at an institutional level. "I gave a few lectures about Tuning in the Tuning Centre that was created in the University. The methodology provoked interest". Tuning centres in Russia constitute local supporting desks and documentation centres with specific resources, in which teachers may collectively support each other by providing mutual counselling.

This type of work supports the development of teachers' knowledge, including pedagogical thinking and concepts in order to develop reflection as a key vehicle for the construction of more permanent teacher awareness and effective and meaningful teaching practices.

Teachers are "agents of change for a better higher education offer(ing)". They are considered to be responsible for creating the best conditions for students to learn and to be in dialogue with the economic, social and global context. Considering the teacher's social role, the bottom-up and cooperative approach promoted by Tuning has been appreciated by participants and the Social Work Group teachers still maintain contacts and exchanges with each other.

The above-mentioned reflections indicate a shared feeling that the implementation of the Tuning approach in each academic institution is at the same time an opportunity to develop a higher education community of 
practice. ${ }^{33}$ Effective changes in university practices, once shared and reflected upon within a wider network are likely to produce significant interactions and to produce resources that should have the potential to affect academic practice inspired by competence-based curricula. In turn, such interactions are likely to foster research practices that would favour monitoring and reflection upon curriculum development and related changes in terms of planning, teaching and learning practices, assessment and evaluation.

\section{Discussion and Conclusions}

The participants in the Tuning Russia project have highlighted many strengths and lessons learnt. The opportunity to share experience and beliefs with colleagues from different institution and from other European Countries increased the value of the project. Workshops and discussions concerning teaching and learning methods have operationalized concepts in higher education practice promoting the development of innovation and excellence. Therefore, they have been very much appreciated by academic teachers. In particular, during the workgroups, attention has been focused on interaction in higher education teaching (such as asking questions, supporting students in providing good ideas, offering help to students or showing concern for student progress, etc..) and the effectiveness of using tools like case studies, role plays, individual or team projects.

Although appropriate assessment and feedback (helpful comments on students' work, quality of feedback on students' progress, appropriate assessment tasks) is one of the six principles for effective higher education teaching according to Ramsden,$^{34}$ due to lack of time and attention being given to other priorities, they have not been sufficiently developed. The issue of evaluation and assessment should probably play a more significant role in the future development of the project, by creating new interactive opportunities for teachers to focus on reflection on evaluation practice, to share problems and to find common solutions, and to find and build together a repository of assessment methods.

The reflection by academic teachers upon the initial implementation of the Tuning approach in Russia points to the opportunity to explore how to

${ }^{33}$ Etienne Wenger, Richard McDermott, and William Snyder, Cultivating communities of practice (Boston: Harvard Business School Press, 2002).

${ }^{34}$ Paul Ramsden, Learning to teach in higher education, 2nd ed. (London: Routledge, 2003). 
establish and to improve communities of practice in the field of competencebased higher education curriculum development. Within this framework Buckley and Giannakopoulos ${ }^{35}$ offer a model and a theoretical framework to assist in the development and improvement of new and existing communities of practices within a higher education institution. The challenge for Tuning Russia would be to foster such communities both within and across academic institutions. Buckley and Giannakopoulos consider that multiple inputs should be taken into consideration when thinking of a higher education community of practices. They explore inputs coming from management, academics, advisers and professional associations. A potential Tuning Russia follow-up research process could take inspiration from the questionnaire drafted by Buckley and Giannakopoulos which takes into account three main types of data: active community of practice members; reasons for preventing a member from participating in a community of practice; and willingness to participate in a community of practice. Collected data is discussed in terms of the relations among domains, communities and practices. In the case of South Africa, where the model has been applied, they point to the fact that management needs to play an active role in the development of communities of practice in order for them to be successful. Such an active role is spelled out in terms of creating awareness among the academic community, educating, encouraging and providing financial and technical support to the community. The key challenges identified by these authors in the case of South Africa seem highly relevant in the case of Tuning Russia. They involve:

- providing a focus on topics important to the academic community, which in the case of Tuning Russia would mean communication of the initial results of the Tuning process in ways that make it relevant to all involved stakeholders;

- finding experienced moderators to coordinate the academic communities, as well as supporting an active core group: an opportunity for Tuning Russia to share and enhance experiences across the Tuning Centres;

- ensuring that academics have time and are encouraged to participate;

- offering opportunities and resources for building personal relationships among academic community members;

${ }^{35}$ Sheryl Buckley and Paul Giannakopoulos, "Technology and tools supporting CoPs," in Knowledge management innovations for interdisciplinary education: organizational applications, ed. Sheryl Buckley and Maria Jakovljevic (USA: IGI Global Publisher, 2012). 
- building on the core values of the university, making it explicit how changes triggered by the Tuning process relate to each academic institution value framework;

- getting academic leaders involved; and

- creating forums for thinking together and sharing information.

An essential aspect developed during the project and to be enhanced and improved in the near future is the individual and collective continuous reflection on the Tuning concepts and tools. Schön ${ }^{36}$ distinguishes between reflection-in-action and reflection-on-action; both are important and must be integrated for the development of awareness of the methodology and on the ways to apply it. Reflection-in-action refers to the process that allows people to reshape what they are working on, while they are working on it. It is an on-going experimentation that helps one find a viable solution. Reflectionon-action refers to "lessons learnt," in which afterwards every person evaluates his/her own process: "we reflect on action, thinking back on what we have done in order to discover how our knowing-in-action may have contributed to an unexpected outcome". ${ }^{37}$

The challenge for academic teachers is to reflect on their teaching practices, re-think and re-designing them from a student-centred perspective. A permanent individual reflection supported by collective reflection within the community allows teachers to significantly improve their understanding of students' needs, as well as to apply the Tuning concepts in specific contexts adapting the methodology and, therefore, to innovate their teaching towards standards of excellence.

\section{Bibliography}

Arter, Judith, and Jan Chappuis. Creating and recognizing quality rubrics. Upper Saddle River, NJ: Pearson/Merrill Prentice Hall, 2007.

Biggs, John. Teaching for Quality Learning at University. Buckingham: Open University Press, 2003.

Buckley, Sheryl and Maria Jakovljevic, eds. Knowledge management innovations for interdisciplinary education: organizational applications. USA: IGI Global Publishers, 2012.

${ }^{36}$ Donald Schön, The reflective practitioner (London: Temple Smith, 1983).

37 Donald Schön, "Teaching artistry through reflection-in-action", in Educating the reflective practitioner (San Francisco, CA: Jossey-Bass Publishers, 1987), 22-40. 
and Paul Giannakopoulos. "Technology and tools supporting CoPs." In Knowledge management innovations for interdisciplinary education: organizational applications, edited by Sheryl Buckley and Maria Jakovljevic. USA: IGI Global Publisher, 2012.

Burón Orejas, Javier. Enseñar a aprender. Introducción a la metacognitión. Bilbao: Mensajero, 1993.

Butler, Debora. L. and Philip Winne. "Feedback and self-regulated learning: a theoretical synthesis." Review of Educational Research 65, 3 (1995): 245-281.

Commission of the European Communities. "A new partnership for the modernisation of universities: the EU Forum for University Business Dialogue.” COM(2009) 158 final. Brussels: European Commission, 2009.

Engeström, Yrjö. "Expansive learning at work: Toward an activity theoretical reconceptualization." Journal of Education and Work 14, 1 (2001): 133-156.

González, Julia, and Robert Wagenaar. TUNING Educational Structures in Europe II. Universities' contribution to the Bologna Process. Final report Project Phase II. Universidad de Deusto / Universiteit Groningen: Deusto University Press, 2005.

Gow, Lin, and David Kember. "Conceptions of teaching and their relationship to student learning." British Journal of Educational Psychology 63 (1993): 20-33.

High Level Group on the Modernisation of Higher Education. "Report to the European Commission on Improving the quality of teaching and learning in Europe's higher education institutions.” Brussels: European Commission, 2013.

Hoidn, Sabine, and Kiira Kärkkäinen. "Promoting Skills for Innovation in Higher Education: A Literature Review on the Effectiveness of Problem-based Learning and of Teaching Behaviours." OECD Education Working Papers $\mathrm{N}^{\circ} 100$. OECD Publishing, 2014.

Karavayeva, Yevgeniya V., and Yelena N. Kovtun. "Adapting the Tuning Programme Profiles to the Needs of Russian Higher Education", Tuning Journal for Higher Education, Issue No. 1 (November 2013): 187-202.

Kember, David. "Teaching beliefs and their impact on students' approach to learning." In Teaching and Learning in Higher Education, edited by Barry Dart and Gillian Boulton-Lewis, 1-25. Camberwell, Australia: Australian Council for Educational Research, 1998.

Lokhoff, Jenneke, Bas Wegewijs, Katja Durkin, Robert Wagenaar, Julia González, Ann Katherine Isaacs, Luigi $\mathrm{F}$ Donà dalle Rose, and Mary Gobbi. A Guide to Formulating Degree Programme Profiles. Bilbao, Groningen, and The Hague: Universidad de Deusto, 2010.

Nicol, David J., and Debra Macfarlane-Dick. "Formative assessment and selfregulated learning: a model and seven principles of good feedback practice." Studies in Higher Education 31, 2 (2006): 199-218.

Norton, Lin, J. T. E. Richardson, J. Hartley, S. Newstead, and J. Mayes. "Teachers' beliefs and intentions concerning teaching in higher education." Higher Education 50 (2005): 537-571. 
Ramsden, Paul. Learning to teach in higher education. 2nd edition. London: Routledge, 2003.

Reddy, Y. Malini, and Heidi Andrade. "A review of rubric use in higher education." Assessment \& Evaluation in Higher Education 35, 4 (2010): 435-448.

Samuelowicz, Katherine, and John D. Bain. "Revisiting academics beliefs about teaching and learning." Higher Education 41(2001): 299-325.

Schön, Donald. The reflective practitioner. London: Temple Smith, 1983.

- "Teaching artistry through reflection-in-action." In Educating the reflective practitioner, 22-40. San Francisco, CA: Jossey-Bass Publishers, 1987.

Scriven, Michael. "The methodology of evaluation." In Perspectives on Curriculum Evaluation (AERA Monograph Series - Curriculum Evaluation), edited by Ralph W. Tyler, Robert M. Gagné, and Michael Scriven. Rand McNally and Co, 1967.

Silverman, David. Interpreting Qualitative Data. Methods for Analysing Talk, Text and Interaction, London: Sage, 2001.

Strobel, Johannes, and Angela van Barneveld. "When is PBL more effective? A meta-synthesis of meta analyses comparing PBL to conventional classrooms." The Interdisciplinary Journal of Problem based Learning 3, 1(2009): 44-58.

Trigwell, Keith, Michael Prosser, and Philip Taylor, "Qualitative differences in approaches to teaching first year university science." Higher Education 27 (1994): 75-84.

Villa Sanchez, Aurelio, and Manuel Poblete Ruiz, eds. Competence-based learning. Tuning Project. Bilbao: University of Deusto, 2008.

Voorhees, Richard A. "Competency-Based Learning Models: A Necessary Future." New directions for institutional research 110 (2001):5-13.

Wenger, Etienne, Richard Arnold McDermott, and William Snyder. Cultivating communities of practice. Boston: Harvard Business School Press, 2002.

Yorke, Mantz. "Formative assessment in higher education: moves towards theory and the enhancement of pedagogic practice." Higher Education 45, 4 (2003): 477-501. 